\title{
Book Review: Transactional Distance and Adaptive Learning: Planning for the Future of Higher Education
}

\author{
Authors: Farhad Saba and Rick L. Shearer (New York: Routledge, 2018, 211 pages) \\ Reviewed by: Abdullah Saykili, Anadolu University
}

Established by Michael G. Moore about fifty years ago, The Theory of Transactional Distance (TTD) offers a view of teaching and learning which posits that distance in educational processes is not only a geographical, but also a psychological one. The idea that three distinct but interplaying variablesdialogue, structure and autonomy - shape the landscape of any educational setting, has provided guiding principles for open and distance learning (ODL).

By developing a renewed perspective on TTD through the lens of systems dynamics, the book Transactional Distanceand Adaptive Learning situates one of the most influential theories in ODL into the center of its focus relating the theory to the changing landscape of higher education. To deal with the challenges triggered primarily by societal changes and the impact of emerging technologies, the authors offer the stakeholders concerned with education, from instructors to policy-makers, a comprehensive and adaptive model based on TTD to assess their current educational practices and develop alternative solutions in order to prepare for the future.

The book begins with a foreword by Michael G. Moore who, through the fable of chickens and owls, encourages the faculty to leave their "academic perch" (Saba \& Shearer, 2018, p. xvi) and share their knowledge and expertise to guide and help the educational institutions better serve for the needs of the society in a time of complexity, uncertainty, and constant change. Both Moore and the authors emphasize the need for a reform of the educational paradigm based on the industrial era. According to the authors, the barriers and the opportunities presented by the current technologies cannot be fully understood while the universities "have one foot in the modern industrial era and another in the emerging postmodern epoch" (Saba \& Shearer, 2018, p. xxiii). Therefore, the efficient and effective utility of current and future technologies depends heavily on transitioning from the industrial school model that focuses on standardized education of masses to the postmodern school model that highlights the needs, characteristics, and demands of the individual, adapting continually and accordingly.

The authors adopt a systems approach in addressing the issues surrounding the educational endeavors of higher education institutions, which is akin to Moore and Kearsley's (2012) systems view of distance education. They present their systematic model in three fundamental universes of systems. The first universe of systems, at the micro level, includes those that allow interaction and communication between learners, faculty, and administrators including hardware, software, and telecommunications systems. The authors also place a special emphasis on Adaptive Learning Systems (ALS) within the software systems since ALS have the potential to optimize the transactional distance in an educational 
setting. ALS, with their abilities to shape the learning environment to better suit the learner needs and characteristics (Ennouamani \& Mahani, 2017), offer a personalized form of education that is actively and dynamically tailored for each learner's learning-related traits, cognitive and experiential standing, as well as his/ her learning context (Spector, 2012). Within this regard, ALS impact the transactional distance that a learner experiences through decreasing the structure of the educational experience and increasing the possibilities for more dialogue and autonomy. The chapter dedicated to ALS sufficiently informs the reader on the current use and effectiveness of ALS in addition to the related concepts and applications, including Adaptive Hypermedia Systems, Adaptive Simulations, and Serious Games. While the title of the book creates an expectation that the reader would find more on the potential link between ALS and the constructs that make up TTD, the authors only touch on this relationship lightly. It would be worthwhile to expand on how ASL can help address dialogue, structure, and autonomy as constructs shaping an individual's educational experience.

At the meso level, the second universe of systems that requires consideration for effective adoption of the principles of TTD are the instructional and curricular systems that accommodate the teaching and learning environments. The authors address instructional design models within a transactional distance vantage point, viewing instructional design models as a continuum rather than "mutually exclusive concepts" (Saba \& Shearer, 2018, p. 114). At the macro level, the third universe of systems that interact extensively with the successful implementation of TTD principles are the management, societal, and global systems that determine and shape the ways in which institutions are supported, funded, and managed. Each system in the model interact and impacts, on a larger or smaller scale, the other systems, and it is the overall interaction of these distinct, but interlocked systems, that determines the efficiency of the transition of a higher educational institution from an industrial school to a postindustrial and postmodern one that can better adapt itself to the changing climate.

The authors present cases at the end of each chapter, which serve not only to exemplify how each system affects the educational practices, but also to clarify the ways in which institutions can handle the challenges imposed by a malfunctioning system. The book also includes a "From Theory to Practice" section that seeks to help stakeholders formulate a unique future for their respective institutions based on the TTD principles through system dynamics modelling methodology (Saba \& Shearer, 2018, p. 182). Within this regard, the book serves both theoretical and practical purposes. The authors also offer a review of selected literature on TTD with a special focus on system dynamics research as an appendix.

In sum, this book addresses the TTD from systems dynamics perspective underscoring that the true value of the emerging technologies can only be realized in educational settings when an educational reform is undertaken through a holistic approach that takes the eight hierarchical systems discussed in this book into consideration. Within this regard, TTD offers a renewed lens toward understanding the complexity of higher education today. TTD, when combined with the system dynamics approach optimizing transactional distance for each learner, has the potential to help visualize and realize a future for higher education which is better equipped to the navigate uncertain waters. 


\section{References}

Ennouamani, S., \& Mahani, Z. (2017). An overview of adaptive e-learning systems. Proceedings of the 2017 Eighth International Conference on Intelligent Computing and Information Systems (ICICIS), Cairo, 342-347. doi:10.1109/ INTELCIS.2017.8260060

Moore, M. G., \& Kearsley, G. (2012). Distance education: A Systems view of online learning (3rd ed.). Belmont, CA: Wadsworth.

Saba, F., \& Shearer, R. L. (2018). Transactional distance and adaptive learning: Planning for the future of higher education. New York, NY: Routledge.

Spector, J . M. (2012). Foreword. In S. Graf, F. Lin, Kinshuk, \& R. McGreal (Eds.), Intelligent and adaptive learning systems: Technology enhanced support for learners and teachers (pp. xvii - xix). Hershey, PA: IGI Global.

\section{Athabasca}

University

(c) ( 